\title{
Primary Healthcare: A 'Jigsaw’ In Reform of the Health Services
}

\section{Krishna Regmi*}

School of Health, Sport and Bioscience, University of East London, UK

Health service reform is on the policy agenda throughout the world. Since the Declaration of Alma-Ata in 1978, much of the discussion about the role of primary healthcare (PHC) in health service reform has centred on the political attraction to decentralised health systems $[1,2]$. The primary goals of PHC are to make health services effective and efficient in the improvement of people's health by focusing on: enhancing health status; reforming health service delivery, healthcare provisions and financial sustainability; and strengthening the local and national health services [3]. The philosophical commitment of the Alma-Ata declaration was that people or service users have the right to access essential and universal healthcare services without any personal and institutional constraints. They should, indeed, be involved in shaping and delivering their own health plans and policies at national, regional and local levels [4]: nothing about us without us [5]. The reform, however, is not one concept in itself and it is highly contested because in many cases it is unlikely that a causal relationship between the aspects of reform and changes in the performance of health systems could be established [6,7]. It has been decades since a commitment was made to improve people's health by spending billions in clinical advancement and infrastructure development globally, but the outcome is rather disappointing because healthcare is still beyond the reach of many poor people. Women and children are suffering, children from poor households are malnourished and at risk of dying and death tolls have increased at an exponential rate like the speed of the 'Bloodhound' car $[3,8]$ ! Penchon et al. [9] argue that 'continued investment in clinical care brings diminishing returns' (p. xxxi). In a similar vein, several authors argue that ill-distribution of resources between central and local government and the limited space provided to the local people to exercise their power in making healthcare decisions, are some of the attributes in the context of the developing world $[10,11]$.

However, many positive changes have materialised including: eradication of small pox, the control of many preventable diseases, medical advancements, modern health technologies such as working with robots, recognition of behavioural research in healthcare research and an initiative to eradicate polio. However, healthcare industries continue to be operated within the control of 'technocrats' and, in many respects, politicians revolve in the centre sphere of health services. During the time of the Alma-Ata declaration, all member states committed to PHC an essential approach to reform health services through transferring power and authority to the local level, keeping people at the centre of healthcare policy, so that people would be more empowered to be able to take some stakes in shaping their own health and wellbeing. We have however, many difficult roads ahead mainly due to different political and institutional contextual environments and at the same time contemporary notions of reform are not uniform. Though healthcare reform is a vastly complex agenda, we can look at $\mathrm{PHC}$ as a policy response for increasing local administration and autonomy of primary care services. This will have different relevance in different systems (e.g. centrally funded and controlled within a strong democratic framework (UK), federalised system (Spain, Canada, USA), provincial countries with weak infrastructures etc). Teasing out system PHC effects of reform approaches from other political and institutional changes is difficult.

The reality of course is that although health reform has much been centred in the policy debate, the outcomes have not been revealed at a satisfactory level. Few of these will come as a surprise and these include a lack of funding, poorly defined concepts, diversity of policy changes, inadequate staffing levels, under-strength skill mix and different driving forces and political and economic motivations behind reform [3]. While accessing and using health services, the public often 'expects and demands the highest quality of care' [12], it is equally important that to bring healthcare success there should be a clearer health policy agenda from a 'system perspective', including better institutional reform, development of health workforce - skill-mix right, political changes, autonomy, restructuring or reorganising of authority, accountability and responsibility to bring positive outcomes amongst the most vulnerable people in the world [13-15].

\section{References}

1. World Health Organization (2006) The World Health Report 2006: Working together for health. WHO, Geneva.

2. World Health Organization (1978) Primary health care: report of the Internationa Conference on Primary Health Care, Alma-Ata, USSR jointly sponsored by the World Health Organization and the United Nations Children's Fund. WHO Geneva.

3. Wang $L$ (2003) Determinants of child mortality in LDCs: empirical findings from demographic and health survey. Health Policy 65: 277-299.

4. Evans D, Pilkington P, McEachran M (2010) Rhetoric or reality? A systematic review of the impact of participatory approaches by UK public health units on health and social outcomes. J Public Health 32: 418-426.

5. Werner D (1998) Nothing about us without us: Developing innovative technologies for, by, and with disabled persons. Health Wrights, Pala Alto, CA

6. World Health Organization (2008) World Health Report 2008 - Primary Health Care- now more than ever. WHO, Geneva.

7. World Health Organization (1995) Decentralisation and health systems change: A framework for analysis. WHO, Geneva.

8. Wagstaff A (2000) Socioeconomic inequalities in child mortality: Comparisons across nine developing countries. Bull World Health Organ 78: 19-29.

9. Penchon D, Guest C, Melzer D, Gray JA (2006) Oxford handbook of public health practice. Oxford University Press, Oxford.

10. Griffin CC (1992) Healthcare in Asia: A comparative study of cost and financing World Bank Regional and Sectoral Studies, World Bank, Washington DC.

11. Peckham S, Exworthy M, Powell M, Greer I (2008) Analysing health services decentralisation in the UK. Health policy and politics, Ashgate, London.

*Corresponding author: Krishna Regmi, School of Health, Sport and Bioscience, University of East London, London, UK, E-mail: Krishna@uel.ac.uk

Received March 20, 2012; Accepted March 22, 2012; Published March 24, 2012

Citation: Regmi K (2012) Primary Healthcare: A 'Jigsaw' In Reform of the Health Services. Primary Health Care: Open Access 2:e103. doi:10.4172/2167 1079.1000e103

Copyright: (c) 2012 Regmi K. This is an open-access article distributed under the terms of the Creative Commons Attribution License, which permits unrestricted use, distribution, and reproduction in any medium, provided the original author and source are credited. 
Citation: Regmi K (2012) Primary Healthcare: A 'Jigsaw' In Reform of the Health Services. Primary Health Care: Open Access 2:e103. doi:10.4172/ $2167-1079.1000 \mathrm{e} 103$

Page 2 of 2

12. Scott G (2011) Join our campaign to enable the best care. Nurs Stand 26: 1.

13. Gauld R (2011) The WHO and primary healthcare reform: mind the implementation gap. Int J Clin Pract 65: 386-390.
14. Bossert T (1996) Decentralisation. Heath policy and system development: An agenda for research, WHO, Geneva.

15. Merson MH, Black RE, Mills AJ (2012) Global health: diseases, programs, systems and policies. (3rdedn), Jones \& Bartlett Learning, London. 